\title{
SÍNDROME DEL SENO SILENTE, UNA CAUSA INFRECUENTE DE ENOFTALMOS
}

\section{SINUS SYNDROME, AN UNCOMMON CAUSE OF ENOPHTHALMOS}

\author{
SÁNCHEZ-DALMAU BF ${ }^{1}$, PASCUAL L ${ }^{2}$, LAO X ${ }^{2}$, MAIZ J ${ }^{2}$
}

\section{RESUMEN}

Caso clínico: Una paciente de 29 años de edad acudió para valoración de sensación subjetiva de asimetría ocular de meses de evolución. El examen oftalmológico apreció un enoftalmos de 3,5 mm y un leve desplazamiento inferior del globo. Una TAC (Tomografía Axial Computerizada) demostró un colapso del seno maxilar, con adelgazamiento y abombamiento inferior del suelo de la orbita. Se confirmó el diagnóstico de síndrome del seno silente. Fue intervenida, practicándose una antrostomía endoscópica con franca mejoría clínica.

Discusión: Se comentan las características clínicas del síndrome del seno silente, así como su diagnóstico, diagnóstico diferencial y tratamiento.

Palabras clave: Enoftalmos, síndrome del seno silente, hipoglobo, sinusitis, antrostomía endoscópica.

\section{ABSTRACT}

Clinical case: A 29-year-old woman presented with a subjective sensation of ocular asymmetry from several months beforehand. Ophthalmological exam showed 3,5 mm right enophthalmos and light hypoglobus. CT (Computerized Tomography) scan showed a collapsed maxillar sinus, and a thinned inferior orbital wall. The diagnosis of silent sinus syndrome was made. An endoscopic maxillary antrostomy with uncinectomy was made with an excellent surgical outcome.

Discussion: Clinical features of silent sinus syndrome are described, including diagnosis, differential diagnosis and treatment (Arch Soc Esp Oftalmol 2007; 82: 125-128).

Key words: Enophthalmos, silent sinus syndrome, hypoglobus, sinusitis, endoscopic antrostomy.

\section{CASO CLÍNICO}

Se presenta el caso de una paciente de 29 años, que acudió a urgencias de nuestro centro refiriendo que tenía «el ojo derecho hundido» de 6 meses de evolución y aportaba fotografías anteriores al problema (fig. 1) para evidenciar ese cambio facial que había sufrido.

No presentaba antecedentes patológicos de interés.

\footnotetext{
Recibido: 20/4/06. Aceptado: 30/10/07.

1 Licenciado en Medicina. Institut Clínic d'Oftalmologia (ICOF). Hospital Clinic i Provincial. Barcelona. España.

2 Licenciado en Medicina. Servicios de Oftalmología y Otorrinolaringología. Hospital Mutua de Terrassa. Terrassa. Barcelona. España. Comunicación presentada parcialmente en el LXXXI Congreso de la S.E.O. (Zaragoza 2005).
} 


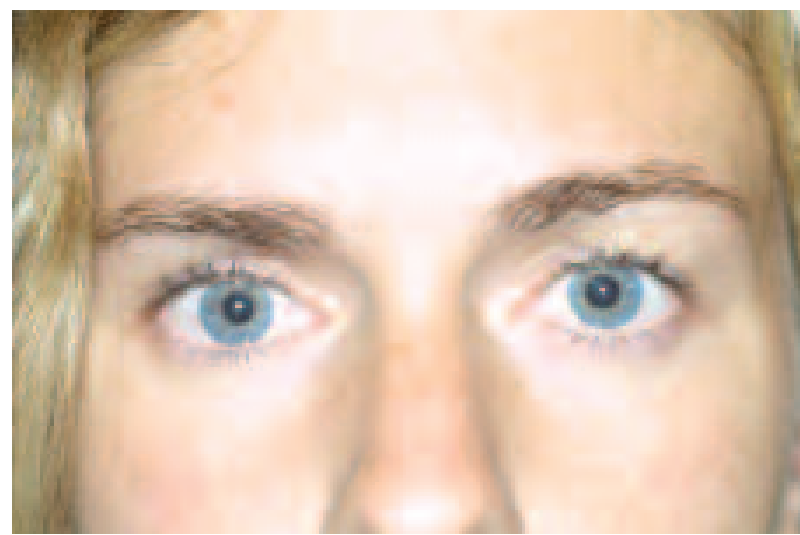

Fig. 1: Aspecto de la paciente varios meses antes del cuadro clínico, con una correcta simetría orbitaria.

La exploración oftalmológica mostró una agudeza visual de 1 en ambos ojos sin corrección con motilidad ocular intrínseca y extrínseca normales. La exoftalmometría era de $12,5 \mathrm{~mm}$ en ojo derecho y de $16 \mathrm{~mm}$ en ojo izquierdo. Se apreciaba un desplazamiento inferior de $1 \mathrm{~mm}$ del globo ocular derecho (fig. 2). Había un aumento del surco palpebral superior, con retracción palpebral superior a la

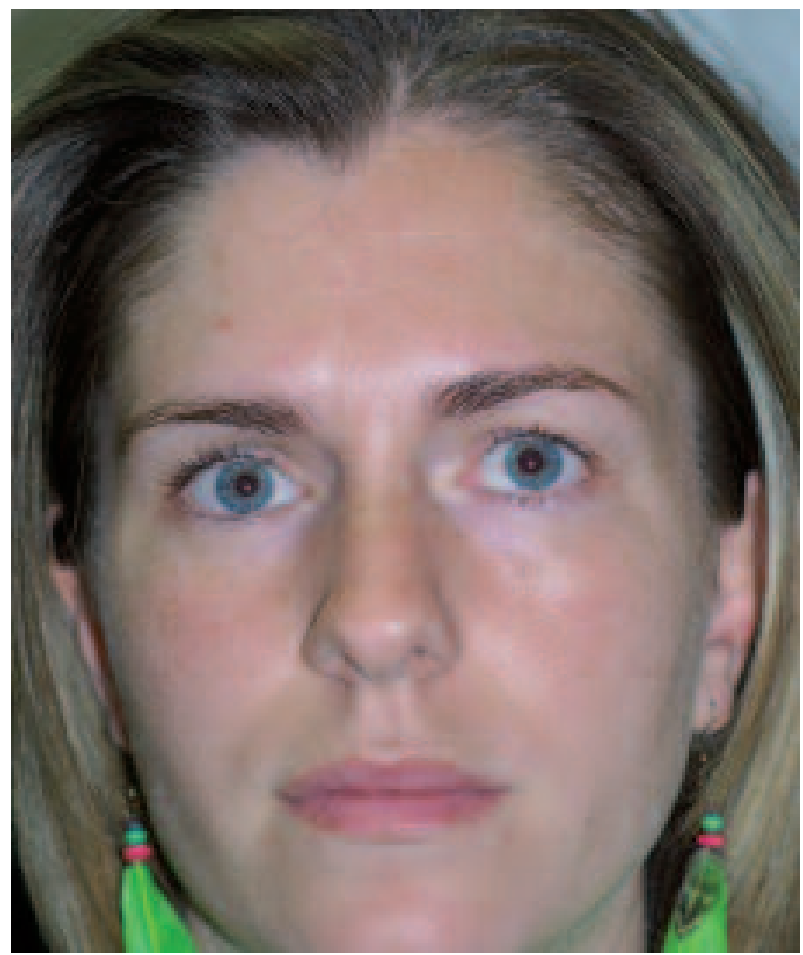

Fig. 2: Obsérvese enoftalmos derecho, leve desplazamiento inferior y asimetría facial evidente.

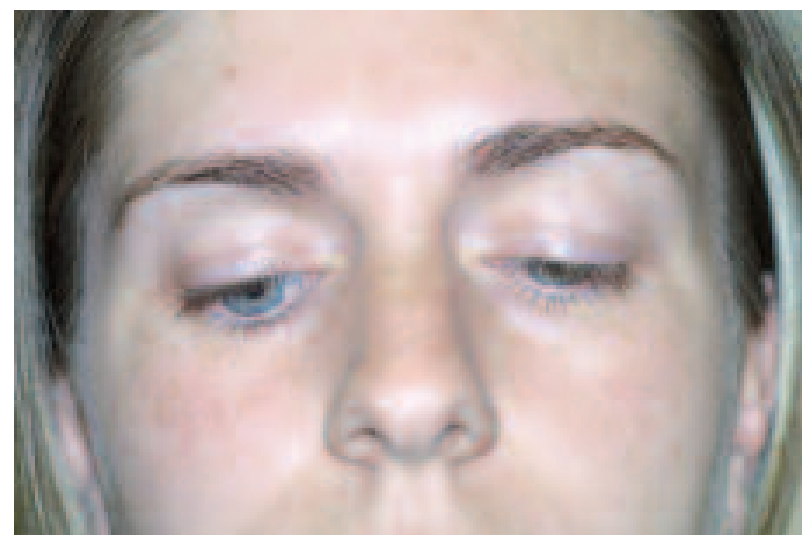

Fig. 3: Retracción palpebral superior del ojo derecho en mirada inferior.

mirada inferior (fig. 3). El resto de la exploración oftalmológica fue normal.

Se realizó una TAC en la que se objetivó un seno maxilar derecho colapsado, con un descenso de volumen, una retracción interna de las paredes y un adelgazamiento y desplazamiento inferior del suelo de la órbita. El proceso uncinado estaba retraído hacia la pared orbitaria, obstruyendo el infundíbulo del seno maxilar (fig. 4).

\section{DISCUSIÓN}

Un subgrupo de pacientes afectos de atelectasia maxilar crónica, con descenso del volumen sinusal

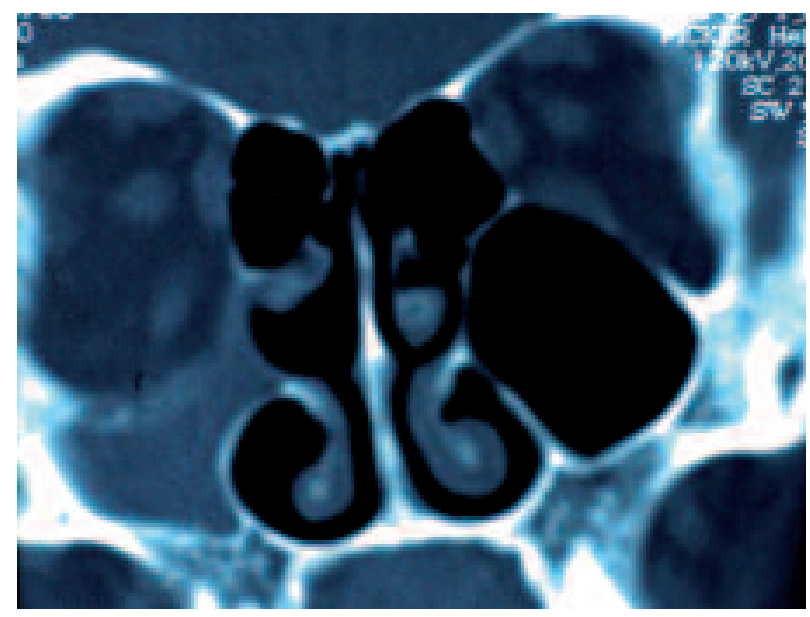

Fig. 4: TAC coronal. Se aprecia seno maxilar derecho colapsado, con desplazamiento abombado inferiormente de su pared superior. Etmoides parcialmente opacificado con engrosamiento mucoso. 
y retracción centrípeta de las paredes maxilares se presentan sin ningún tipo de historia nasal o sinusal, salvo la sustancial deformación de las paredes óseas y el enoftalmos. Este subgrupo ha sido denominado con el nombre de síndrome del seno silente (SSS). Aunque fue inicialmente descrito por Montgomery en la epoca pre TAC, el concepto fue introducido por Soparkar et al (1) en 1994.

Desde entonces la asociación entre enoftalmos y atelectasia maxilar se ha descrito con mayor frecuencia, tanto en la literatura otorrinolaringológica como en la oftalmológica.

El síntoma de presentación del SSS es un enoftalmos espontáneo de varias semanas o meses de evolución. Típicamente afecta entre la 3. ${ }^{\mathrm{a}}$ y 5 . $^{\mathrm{a}}$ década, sin diferencia de sexo y, al parecer, con menor incidencia en fumadores (2).

Muchas veces el paciente consulta al oftalmólogo para evaluación de asimetría ocular, pudiendo llegar a ser etiquetado de exoftalmos contralateral.

Clínicamente cursa con enoftalmos e hipoglobo. Los síntomas que puede presentar son: cambios en la hemifacies afecta, asimetría orbitaria, hundimiento del surco orbitario palpebral superior, desaparición de la línea del pliegue palpebral, retracción palpebral (más aparente que real por la distopia del globo ocular), retraso del párpado superior en la mirada inferior, y muy ocasionalmente, lagoftalmos. De forma menos frecuente pueden referir diplopia, que es casi siempre vertical, blefaroptosis, oscilopsia o incluso percepción de un sonido audible con el parpadeo debido al atrapamiento de aire en los recesos conjuntivales. La función visual está típicamente conservada.

La fisiopatología de la atelectasia maxilar crónica es controvertida. Aunque algunos autores postulan la presencia de un seno hipoplásico de base, otros sugieren un proceso adquirido en el que la retracción de las paredes del seno maxilar se produce por la presión negativa endosinusal inducida por la obstrucción del ostium maxilar en el meato medio. Se apoyan para esta afirmación en imágenes radiográficas normales en pacientes con estudios previos al desarrollo del trastorno.

Según Kass, la atelectasia maxilar se produce en 3 estadios, basado en el grado de deformación maxilar. El primer estadio se caracteriza por deformidad de la membrana y lateralización de la fontanela maxilar, el segundo estadio por deformidades óseas (retracción de una o más paredes del seno) y en el estadio tres se presentan los signos clínicos de enoftalmos, hipoglobo y/o deformidad de la hemifacies (3).
La exploración de elección es la TAC, tanto axial como coronal. Los hallazgos radiológicos incluyen colapso de la pared medial infundibular, obstrucción del complejo osteomeatal, lateralización del proceso uncinado, opacificación del seno maxilar, retracción de las paredes posterolateral, superior, anterior y medial del seno, aumento de las fosas pterigopalatina e infratemporal, elevación de la fosa canina y relativo desplazamiento lateral del canal infraorbitario (4). En cuanto a la órbita, se aprecia un desplazamiento inferior del globo y de los músculos extraoculares, con mayor afectación del músculo recto inferior. El tejido blando orbitario aparece normal.

Puede aparecer una imagen de pseudoneumoórbita por el aire atrapado bajo el párpado superior y en los recesos conjuntivales superiores (5).

Se debe realizar diagnóstico diferencial con otras causas de enoftalmos e hipoglobo como traumatismo, carcinoma escirro, variz orbitaria, osteomielitis, síndrome de Parry-Romberg, esclerodermia lineal y lipodistrofia.

El objetivo del tratamiento está orientado a restablecer una aireación normal del seno maxilar y la posición normal del globo ocular.

Primero se debe proceder quirúrgicamente a la reparación del seno con una antrostomía maxilar endoscópica con uncinectomía.

En cuanto al enoftalmos y el hipoglobo, puede corregirse simultáneamente al seno, con la colocación de un implante orbitario o se puede esperar a una posible mejoría clínica tras el primer acto quirúrgico $(50 \%)$ y realizar la reconstrucción orbitaria en un segundo tiempo si es necesaria.

\section{BIBLIOGRAFÍA}

1. Soparkar CN, Patrinely JR, Cuaycong MJ, Dailey RA, Kersten $R C$, Rubin PA, et al. The silent sinus syndrome. A cause of spontaneous enophthalmos. Ophthalmology 1994; 101: 772-778.

2. Rose GE, Sandy C, Hallberg L, Moseley I. Clinical and radiologic characteristics of the imploding antrum, or «silent sinus», syndrome. Ophthalmology 2003; 110: 811818.

3. Kass ES, Salman S, Rubin PA, Weber AL, Montgomery WW. Chronic maxillary atelectasis. Ann Otol Rhinol Laryngol 1997; 106: 109-116.

4. Geraghty JJ, Dolan KD. Computed tomography of the hypoplastic maxillary sinus. Ann Otol Rhinol Laryngol 1989; 98: 916-918.

5. Buono LM. The silent sinus syndrome: maxillary sinus atelectasis with enophthalmos and hypoglobus. Curr Opin Ophthalmol 2004; 15: 486-489. 